\title{
Changes in epidemiology of rotavirus in the Triângulo Mineiro region of Brazil: lack of two consecutive rotavirus seasons
}

\author{
A.C.B. Dulgheroff ${ }^{1}$, E.F. Figueiredo ${ }^{1}$, V.S. Gouvêa ${ }^{2}$ and A.L.S. Domingues ${ }^{1}$ \\ ${ }^{1}$ Instituto de Ciências Biológicas e Naturais, Disciplina de Microbiologia, Universidade Federal do Triângulo Mineiro, \\ Uberaba, MG, Brasil \\ ${ }^{2}$ Departamento de Virologia, Instituto de Microbiologia, Universidade Federal do Rio de Janeiro, Rio de Janeiro, RJ, Brasil
}

\begin{abstract}
Rotaviruses are the main cause of infantile acute diarrhea, and a monovalent (G1P[8]) vaccine against the virus was introduced into the Brazilian National Immunization Program for all infants in March 2006. The objectives of this study were to determine the rate and genotype distribution of rotavirus causing infantile diarrhea in the Triângulo Mineiro region of Brazil during 2011-2012 and to assess the impact of local vaccination. Fecal specimens were analyzed for detection and characterization of rotavirus using polyacrylamide gel electrophoresis, reverse transcription followed by polymerase chain reaction (PCR), and PCR-genotyping assays. Overall, rotavirus was diagnosed in 1.7\% (6/348) of cases. Rotavirus positivity rates decreased $88 \%$ [95\% confidence intervals $(\mathrm{Cl})=15.2,98.3 \% ; \mathrm{P}=0.026$ ] in 2011 and $78 \%(95 \% \mathrm{Cl}=30.6,93.0 \%$; $\mathrm{P}=0.007)$ in 2012 when compared with available data for baseline years (2005/2006) in Uberaba. In Uberlândia, reductions of $95.3 \%(95 \% \mathrm{Cl}=66.0,99.4 \% ; \mathrm{P}=0.002)$ in 2011 , and $94.2 \%(95 \% \mathrm{Cl}=56.4,99.2 \% ; \mathrm{P}=0.004)$ in 2012 were also observed compared with data for 2008. The circulation of rotavirus G2P[4] strains decreased during the period under study, and strains related to the $\mathrm{P}[8]$ genotype reemerged in the region. This study showed a marked and sustained reduction of rotavirus-related cases, with a lack of rotavirus in the 2011 and 2012 seasons, suggesting a positive impact of the vaccination program.
\end{abstract}

Key words: Rotavirus; Infantile diarrhea; Surveillance; Genotyping

\section{Introduction}

Rotaviruses, members of the genus Rotavirus, family Reoviridae, are important agents of acute gastroenteritis in children and in many young animal species worldwide. The viral particle is formed by 11 segments of doublestranded RNA (dsRNA) surrounded by a triple capsid. The outer layer is composed of VP7 and VP4 proteins, which are used for a dual classification system, defining $G$ and $P$ types, respectively. The most prevalent combinations causing infection in humans worldwide are genotypes $\mathrm{G} 1$, G2, G3, G4, and G9 associated with P[4] or P[8] (1), but the circulating G/P type of human rotavirus can change dramatically over seasons and regions, representing a challenge to the vaccines RotaTeq ${ }^{\mathrm{TM}}$ and Rotarix ${ }^{\mathrm{TM}}$ currently in use in several countries. Rotavirus vaccines aim at preventing infant death and controlling severe dehydrating diarrhea in children less than 5 years of age. Therefore, following the recommendation of the World Health Organization, several countries have included rotavirus vaccine in their national pediatric immunization programs (2). In Brazil, Rotarix was introduced in March 2006 and has been provided free of charge to all infants. The impact of vaccination on diarrhea-associated mortality and hospitalization was recently evaluated among middle-income Latin American countries (Mexico, Brazil, El Salvador, and Panama), and reductions of $22-41 \%$ and $17-51 \%$ were estimated, for mortality and hospitalization, respectively. A significant reduction in rotavirus hospitalizations (59-81\%) among children younger than 5 years of age was also observed (3).

Monitoring the prevalence and diversity of rotavirus strains during the epidemic seasons in different localities is essential to understanding the epidemiology of the virus in the global context, mainly after the availability of the vaccines. Previous studies described the prevalence and genotypes of rotavirus strains causing diarrhea in infants and children from Triângulo Mineiro, MG, Brazil $(4,5)$. Those

Correspondence: A.L.S. Domingues, Instituto de Ciências Biológicas e Naturais, Disciplina de Microbiologia, Universidade Federal do Triângulo Mineiro, Praça Manoel Terra, 330, 38025-015 Uberaba, MG, Brasil. Fax: +55-34-3312-1487. E-mail: andredomingues@dcb.uftm.edu.br 
studies corresponded to the previous period, from September 2005 to December 2010, and covered the first 4 years subsequent to introduction of the Rotarix vaccine into the national immunization program. In the present study, surveillance data from the 5th and 6th postvaccination years are reported.

\section{Material and Methods}

This laboratory-based surveillance study was conducted in 2011 and 2012. Fecal specimens from hospitalized or outpatient children up to 10 years of age and who presented acute gastroenteritis were collected in the following centers: Laboratório Jorge Furtado Medicina Diagnóstica in Uberaba and IPAC Medicina Diagnóstica in Uberlândia. These two laboratories collect and analyze specimens from private and public hospitals as well as pediatric clinics. Uberaba ( 300,000 inhabitants) and Uberlândia ( 650,000 inhabitants) are the largest cities of the Triângulo Mineiro region in West Minas Gerais. They are approximately $100 \mathrm{~km}$ apart and share high living standards and other social conditions.

For rotavirus detection, the viral dsRNA was extracted from stools by the silica method, as previously described (6), and submitted to polyacrylamide gel electrophoresis (PAGE) (7). Migration patterns of the rotavirus genome segments detected by PAGE were used to classify the strains according to the groups and electropherotypes. Positive specimens were genotyped by reverse transcription-polymerase chain reaction (RT-PCR) amplification and PCR-typing assays to determine VP4 and VP7 genotypes as originally described (8-11).

Rotavirus positivity rates obtained in this study were compared with data available from the baseline years $(4,5)$, corresponding to the same analysis methods. Confidence intervals (Cls) of $95 \%$ for the percentages of rotavirus positivity decrease were calculated using the $X^{2}$ test for independence, and $\mathrm{P}<0.05$ was considered to be statistically significant.

This study was approved by the Ethics Committee of the Universidade Federal do Triângulo Mineiro (UFTM; \#672).

\section{Results}

Overall, rotavirus was diagnosed in $1.7 \%(6 / 348)$ of the cases, and rotavirus infections accounted for $7.7 \%(3 / 39)$ of the hospitalizations and $1 \%(3 / 309)$ of outpatient attendance due to diarrhea in 2011-2012 (Tables 1 and 2). These few cases were found scattered year-round with no recognizable seasonal clustering. The rotavirus prevalence in Uberaba and Uberlândia was 2.7\% (4/147) and 1.0\% (2/ 201), respectively. In contrast with this marked reduction observed in rotavirus cases, the number of specimens collected from children with gastroenteritis did not substantially decrease over the years in the region, eliminating the possibility of bias due to specimen collection.
Table 1. Distribution of acute diarrhea and rotavirus-related cases in hospitalized patients and outpatients in Uberaba during rotavirus season (May to December) and non-rotavirus season (January to April), 2011-2012.

\begin{tabular}{llll}
\hline Period & \multicolumn{3}{c}{ No. positive samples/ } \\
& \multicolumn{3}{c}{ No. samples tested (\%) } \\
\cline { 2 - 4 } & Inpatient & Outpatient & \multicolumn{1}{c}{ Total } \\
\hline 2011 & & & \\
May-December & $1 / 20(5.0)$ & $0 / 36(0.0)$ & $1 / 56(1.8)$ \\
January-April* & $0 / 0(0.0)$ & $0 / 0(0.0)$ & $0 / 0(0.0)$ \\
2012 & & & \\
May-December & $1 / 11(9.0)$ & $1 / 27(3.7)$ & $2 / 38(5.3)$ \\
January-April & $1 / 4(25.0)$ & $0 / 49(0.0)$ & $1 / 53(1.9)$ \\
Total & $3 / 35(8.6)$ & $1 / 112(0.9)$ & $4 / 147(2.7)$ \\
\hline
\end{tabular}

*Fecal samples were not collected in this period.

Rotavirus positivity rates decreased $88 \%(95 \% \mathrm{Cl}=15.2$, $98.3 \% ; \mathrm{P}=0.026)$ in 2011 and $78 \%(95 \% \mathrm{Cl}=30.6,93.0 \%$; $\mathrm{P}=0.007)$ in 2012 when compared with available baseline years (2005/2006) in Uberaba. In Uberlândia, reductions of $95.3 \%(95 \% \mathrm{Cl}=66.0,99.4 \% ; \mathrm{P}=0.002)$ in 2011 and $94.2 \%$ $(95 \% \mathrm{Cl}=56.4,99.2 \% ; \mathrm{P}=0.004)$ in 2012 were also observed compared with 2008 (Table 3). These marked reductions of rotavirus infections were evidenced in both inpatients and outpatients.

The six rotavirus-positive samples presented characteristic group A electrophoretic patterns: 2 samples with short patterns were genotyped as G2P[4] and G3P[4], while, among the 4 long-profile samples, 2 corresponded to G3P[8] genotypes, 1 was a P[8] strain with untypeable $\mathrm{G}$, and in sample 4 neither $\mathrm{G}$ or $\mathrm{P}$ genotypes could be set. Information on the vaccination history of the children was not available; however, among the rotavirus cases, only the child infected with a G3P[4] strain would not be ageeligible for vaccination.

Table 2. Distribution of acute diarrhea and rotavirus-related cases in hospitalized patients and outpatients from Uberlândia during rotavirus season (May to December) and non-rotavirus season (January to April), 2011-2012.

\begin{tabular}{lccc}
\hline Period & \multicolumn{3}{c}{ No. positive samples/ } \\
& \multicolumn{3}{c}{ No. samples tested (\%) } \\
\cline { 2 - 4 } & Inpatient & Outpatient & Total \\
\hline 2011 & & & \\
May-December & $0 / 0(0.0)$ & $0 / 45(0.0)$ & $0 / 45(0.0)$ \\
January-April & $0 / 4(0.0)$ & $1 / 64(1.6)$ & $1 / 68(1.5)$ \\
2012 & & & \\
May-December & $0 / 0(0.0)$ & $1 / 46(2.2)$ & $1 / 46(2.2)$ \\
January-April & $0 / 0(0.0)$ & $0 / 42(0.0)$ & $0 / 42(0.0)$ \\
Total & $0 / 4(0.0)$ & $2 / 197(1.0)$ & $2 / 201(1.0)$ \\
\hline
\end{tabular}


Table 3. Distribution of acute diarrhea and rotavirus-related cases in hospitalized patients and outpatients in Uberaba and Uberlândia during 2011 and 2012 compared to baseline years.

\begin{tabular}{|c|c|c|c|c|c|}
\hline \multirow[t]{2}{*}{ Year } & \multicolumn{3}{|c|}{ No. positive samples/No. samples tested (\%) } & \multirow[t]{2}{*}{$\%$ Rotavirus decrease $(95 \% \mathrm{Cl})$} & \multirow[t]{2}{*}{$\mathrm{P}$} \\
\hline & Inpatient & Outpatient & Total & & \\
\hline \multicolumn{6}{|l|}{ Uberaba } \\
\hline $2005 / 2006^{*+}$ & $8 / 39(20.5)$ & $31 / 221(14)$ & $39 / 260(15.0)$ & Baseline year & NA \\
\hline $2007^{\#}$ & $24 / 62(38.7)$ & $9 / 36(25.0)$ & $33 / 98(33.7)$ & NA & NA \\
\hline $2008^{\#}$ & $1 / 6(16.7)$ & $4 / 72(5.6)$ & $5 / 78(6.4)$ & NA & NA \\
\hline $2009^{\#}$ & $0 / 6(0.0)$ & $1 / 32(3.1)$ & $1 / 38(2.6)$ & NA & NA \\
\hline 2011 & $1 / 20(5.0)$ & $0 / 36(0.0)$ & $1 / 56(1.8)$ & 88.0 (15.2 to 98.3$)$ & 0.026 \\
\hline 2012 & $2 / 15(13.3)$ & $1 / 76(1.3)$ & $3 / 91(3.3)$ & 78.0 (30.6 to 93.0$)$ & 0.007 \\
\hline \multicolumn{6}{|l|}{ Uberlândia } \\
\hline $2008^{\#}$ & $8 / 14(57.1)$ & $12 / 91(13.2)$ & $20 / 105$ (19.0) & Baseline year & NA \\
\hline $2009^{\#}$ & $0 / 17(0.0)$ & $1 / 144(0.7)$ & $1 / 161(0.6)$ & NA & NA \\
\hline $2010^{\#}$ & $10 / 15(66.7)$ & $6 / 135(4.4)$ & $16 / 150(10.7)$ & NA & NA \\
\hline 2011 & $0 / 4(0.0)$ & $1 / 109(0.9)$ & $1 / 113(0.9)$ & 95.3 (66.0 to 99.4$)$ & 0.002 \\
\hline 2012 & $0 / 0(0.0)$ & $1 / 88(1.1)$ & $1 / 88(1.1)$ & 94.2 (56.4 to 99.2$)$ & 0.004 \\
\hline
\end{tabular}

${ }^{*}$ Period of September 2005 to December 2006. ${ }^{+}$Data extracted from Domingues et al. (4). ${ }^{\#}$ Data extracted from Dulgheroff et al. (5). NA: not applicable. The chi-square test was used for statistical analyses.

\section{Discussion}

A marked decline in hospitalizations and outpatient attendance due to rotavirus diarrhea was observed in 2011 and 2012 in 2 cities of the Triângulo Mineiro region when compared with baseline years (2005/2006 in Uberaba or 2008 in Uberlândia) $(4,5)$. Two studies comparing the preand postvaccine years also demonstrated a significant decrease in rotavirus prevalence $(12,13)$. Both surveys analyzed samples of patients from emergency and inpatient wards; one was carried out in a private hospital from São Paulo State, Southeast Brazil, comprising the period from 2004 to 2008, and the other was performed from 2006 to 2009 in El Salvador, a low-middle-income country of Central America that also adopted the Rotarix vaccine. Surveillance studies comprising samples after 2010 are scarce; however, in the United States a high-income country that uses RotaTeq and Rotarix vaccines, the National Respiratory and Enteric Virus Surveillance System also reported a decline of $65 \%$ to $84 \%$ in rotavirus detection rates in the 2010-2012 seasons compared with the prevaccine baseline (14). A study in Argentina, a middle-income country in South America that has not implemented the rotavirus vaccine in the national immunization program, analyzed cases of acute diarrhea in hospitalized and ambulatory patients younger than 5 years of age between 2009 and 2011, and the results showed that rotavirus detection rates remained relatively constant throughout the study period, with an average of $29.5 \%$ (15). Furthermore, the prevalence of rotavirus in 64 countries where vaccines have not been widely implemented was high in 2011 , varying between $37 \%$ and $53 \%$ in children hospitalized with diarrhea (16). Therefore, the marked decline in rotavirus disease probably reflects the benefits of vaccination programs in both developed and developing countries, because it was specifically observed in countries that have introduced rotavirus vaccine in their national childhood immunization program.

A prior study on rotavirus-associated gastroenteritis in Uberaba in 2005/2006 showed the co-circulation of longelectropherotype rotaviruses with a great diversity of genotypes and the emergence of short-electropherotype strains associated with the G2P[4] genotype by mid-2006, shortly after the implementation of the national vaccination program (4). Great diversity and complex mixtures of strains were typical features of the epidemiology of rotavirus infections in Brazil during prevaccination times. The emergence of short G2P[4] strains during the 2006 season at the beginning of the vaccination program was also detected in a similar sentinel study in Rio de Janeiro (17) and by 2008 was found to be widespread across the Brazilian territory including the Northern states (18). The next study, conducted in Uberaba and Uberlândia from 2007 to 2010, demonstrated the almost exclusive circulation of genotype G2P[4] strains that peaked in 2007, disappeared in 2009, and reappeared to a lesser extent in 2010 in Uberlândia, in a seemingly full epidemic cycle, with its typical primary and secondary curves (5). In the present follow-up study, further reduction in rotavirus cases, probably due to the exhaustion of the natural epidemic cycle of G2P[4] strains and to the benefits of vaccination, has resulted in the absence of an epidemic strain and lack of the annual epidemic periods sustained for two consecutive years (2011-2012) in the Triângulo Mineiro region.

Diarrhea cases associated with genotype $\mathrm{G} 1$ or $\mathrm{P}[8]$ strains were last detected in the Triângulo Mineiro region in August 2006, and remained undetected until the end of 
the current study. However, three cases exclusively related to genotype P[8] reappeared in 2012; two of those cases were associated with $\mathrm{G} 3$, the major genotype of rotavirus strains found in small domestic and wild mammals, particularly in cats and dogs. Rare human cases associated with rotavirus genotypes common to animal strains and often detected as mixtures of strains in a single specimen, such as the G5G10Pnon-typed (NT) case in Uberaba in 2009, and the G3P [8]P[4] and G3P[NT] cases in Uberlândia in 2008 and 2009, respectively, have been considered isolated cases of interspecies transmission through water or soil contaminated with animal feces. Because rotaviruses infect a large number of animal species, they undergo frequent reassortment upon natural infections and may occasionally be transmitted to humans (19), and such sporadic background cases are expected to continue to occur everywhere, even in vaccinated populations. However, the detection of G3P[8] in single infections and in both cities might indicate its recent reintroduction into the local pool of circulating strains, signaling a new trend in the epidemiology of rotavirus genotype G3P[8]. The decline in rotavirus G2P[4] strains after 2008-2009 and the reemergence of G1P[8] and G3P[8] strains have been reported in other studies from Brazil $(18,20)$; continuous

\section{References}

1. Estes MK, Kapikian AZ. Rotaviruses. In: Knipe DM, Howley PM (Editors), Fields virology. Philadelphia: Lippincott Williams \& Williams; 2007. p 1917-1974.

2. World Health Organization. Rotavirus vaccines. Wkly Epidemiol Rec 2007; 82: 285-295.

3. Desai R, Oliveira LH, Parashar UD, Lopman B, Tate JE, Patel MM. Reduction in morbidity and mortality from childhood diarrhoeal disease after species A rotavirus vaccine introduction in Latin America - a review. Mem Inst Oswaldo Cruz 2011; 106: 907-911, doi: 10.1590/S0074-02762011000800002.

4. Domingues AL, Morais AT, Cruz RL, Moreira LP, Gouvea VS. Rotavirus-associated infantile diarrhea in Uberaba, Minas Gerais, on the wake of the Brazilian vaccination program. J Clin Virol 2008; 43: 298-301, doi: 10.1016/j.jcv.2008.07.008.

5. Dulgheroff AC, Figueiredo EF, Moreira LP, Moreira KC, Moura LM, Gouvea VS, et al. Distribution of rotavirus genotypes after vaccine introduction in the Triangulo Mineiro region of Brazil: 4-Year follow-up study. J Clin Virol 2012; 55: 67-71, doi: 10.1016/j.jcv.2012.06.003.

6. Boom R, Sol CJ, Salimans MM, Jansen CL, Wertheim-van Dillen PM, van der Noordaa J. Rapid and simple method for purification of nucleic acids. J Clin Microbiol 1990; 28: 495503.

7. Pereira HG, Azeredo RS, Leite JP, Barth OM, Sutmoller F, de Farias V, et al. Comparison of polyacrylamide gel electrophoresis (PAGE), immuno-electron microscopy (IEM) and enzyme immunoassay (EIA) for the rapid diagnosis of rotavirus infection in children. Mem Inst Oswaldo Cruz 1983; 78: 483-490, doi: 10.1590/S0074-02761983000400012.

8. Gouvea V, Glass RI, Woods P, Taniguchi K, Clark HF, Forrester $\mathrm{B}$, et al. Polymerase chain reaction amplification follow-up studies are essential to monitor rotavirus strain circulation for a better evaluation of the effect of vaccine on the dynamics of rotavirus epidemiology.

The use of a convenience sample and the relatively small sample size are limitations of this study. Therefore, these results do not describe the Triângulo Mineiro population as a whole. Nevertheless, compared with previous studies using the same methodology and design $(4,5)$, our data continue to suggest a reduction in prevalence and important changes in the epidemiology of rotavirus disease in the region, 5 to 6 years after vaccine introduction into the Brazilian Public Health System. The marked and sustained reduction in hospitalizations and outpatient attendance found in this study, skipping two consecutive rotavirus seasons, most likely represents long-term public health benefits of the vaccination program.

\section{Acknowledgments}

We thank the laboratories Jorge Furtado Medicina Diagnóstica (Uberaba) and IPAC Medicina Diagnóstica (Uberlândia). A.C.B. Dulgheroff received a PhD fellowship from CAPES/REUNI, Brasília, Brazil. and typing of rotavirus nucleic acid from stool specimens. J Clin Microbiol 1990; 28: 276-282.

9. Gouvea V, Santos N, Timenetsky MC. Identification of bovine and porcine rotavirus $G$ types by PCR. J Clin Microbiol 1994; 32: 1338-1340.

10. Gouvea V, Santos N, Timenetsky MC. VP4 typing of bovine and porcine group A rotaviruses by PCR. J Clin Microbiol 1994; 32: 1333-1337.

11. Gentsch JR, Glass RI, Woods P, Gouvea V, Gorziglia M, Flores $\mathrm{J}$, et al. Identification of group A rotavirus gene 4 types by polymerase chain reaction. J Clin Microbiol 1992; 30: 1365-1373.

12. Safadi MA, Berezin EN, Munford V, Almeida FJ, de Moraes JC, Pinheiro CF, et al. Hospital-based surveillance to evaluate the impact of rotavirus vaccination in Sao Paulo, Brazil. Pediatr Infect Dis J 2010; 29: 1019-1022.

13. Yen C, Armero Guardado JA, Alberto P, Rodriguez Araujo DS, Mena C, Cuellar E, et al. Decline in rotavirus hospitalizations and health care visits for childhood diarrhea following rotavirus vaccination in El Salvador. Pediatr Infect Dis J 2011; 30: S6-S10, doi: 10.1097/INF.0b013e3181fefa05.

14. Tate JE, Haynes A, Payne DC, Cortese MM, Lopman BA, Patel MM, et al. Trends in national rotavirus activity before and after introduction of rotavirus vaccine into the national immunization program in the United States, 2000 to 2012. Pediatr Infect Dis J 2013; 32: 741-744, doi: 10.1097/INF. 0b013e31828d639c.

15. Degiuseppe JI, Giovacchini C, Stupka JA. [Rotavirus epidemiology and surveillance in Argentina: 2009-2011]. Arch Argent Pediatr 2013; 111: 148-154, doi: 10.5546/aap. 2013.148. 
16. Parashar U, Steele D, Neuzil K, Quadros C, Tharmaphornpilas $P$, Serhan $F$, et al. Progress with rotavirus vaccines: summary of the Tenth International Rotavirus Symposium. Expert Rev Vaccines 2013; 12: 113-117, doi: 10.1586/erv.12.148.

17. Gouvea VS, Domingues AL, Naveca FG, Pedro AR, Bevilacqua CC. Changing epidemiology of rotavirus-related hospitalizations in Rio de Janeiro, Brazil, from 2002 to 2006. Open Virol J 2007; 1: 47-50, doi: 10.2174/18743579007010 10047.

18. Soares LS, Lobo PS, Mascarenhas JD, Neri DL, Guerra SF, de Oliveira AS, et al. Identification of lineage III of G12 rotavirus strains in diarrheic children in the Northern Region of Brazil between 2008 and 2010. Arch Virol 2012; 157: 135139, doi: 10.1007/s00705-011-1111-z.

19. Gouvea V, Brantly M. Is rotavirus a population of reassortants? Trends Microbiol 1995; 3: 159-162, doi: 10.1016/S0966842X(00)88908-8.

20. Carvalho-Costa FA, Volotao EM, de Assis RM, Fialho AM, de Andrade JS, Rocha LN, et al. Laboratory-based rotavirus surveillance during the introduction of a vaccination program, Brazil, 2005-2009. Pediatr Infect Dis J 2011; 30: S35-S41, doi: 10.1097/INF.0b013e3181fefd5f. 